\title{
Cloud-Based Approach for Tracking and Monitoring of Hay Bales in Smart Agriculture
} Ilpo Pölönen, Antti Suokannas, \& Antti Juntunen

\author{
I By creating a digital inventory of feed bales, cloud baling eases bureaucracy \\ and enables fluent and reliable roughage e-commerce. " \\ Maaseudun Tulevaisuus \\ In a Finnish agricultural morning paper \\ Sept 27, 2019
}

\begin{abstract}
The introduction of new technology to agriculture has resulted in enormous amounts of data and their handling and utilization challenge. Data is typically gathered from several sources such as field sensors, machines, industrial processes, different laboratories and officials. This has led to several complicated systems that are not always compatible. Farmers are confused, unaware, and face challenges in seeing the benefits for their business in relation to the time required. This paper introduces an automatic digital tracking and monitoring system for round feed bales on farms. In this system, bale data from sensors, switches, and a GPS-device in the baling machine are collected by hardware and sent to the cloud with the bale ID read from a RFID tag attached to each bale. A digital inventory of bales forms instantly, and baling can be followed on the map application with a mobile device. Data in the cloud is utilized for the farmer's user interface. The farmer can manage and do various operations with bales. An important outcome is the yield report, showing basic statistics, quantities, and qualities of bales in a digitalized field parcel. If the farmer wants to sell bales, this can easily be done with the tool. It makes sales by connecting the farmer to an e-commerce portal. A key question and challenge to be resolved involves who owns the data. All the benefits of digitalization can be achieved only with good cooperation and mutual agreement from farmers who want to have control of their data under all circumstances.
\end{abstract}

\section{Introduction}

In Finland, farm size compared with many other European countries is small, though increasing steadily. Bigger farm size in most cases enables better utilization of new technology, automation, and digitalization. With increasing farm size, a farmer's work turns more into a manager's, instead of doing the work by themselves.

A farmer's work focuses on allocating limited resources to their most important duties, while using contractors for capital intensive works. This is typically the way new technology enters agriculture in Finland also, as contractors have bigger and technologically advanced machinery. In the middle of the 2010's, use of contractors was still low compared to many other European countries. According to research from the Work Efficiency Institute (TTS), contractor use is increasing steadily (Palva, 2019).
Regarding data management, several current large projects aim to harmonize and standardize data handling and storage. A major question surrounds the ownership and management of farm data (VillaHenriksen et al., 2020), the cornerstone for farmers' participation and cooperation to develop these systems. A project to harmonize data flow between different tractor makes and implements was launched already in the 1990's. It is called the ISO 11783 series of standards (marked name ISOBUS) "Tractors and machinery for agriculture and forestry - Serial control and communication data network". The purpose of ISO 11783 standard is to specify the method and format of data transfer between sensors, actuators, control elements, information storage, and display units, whether mounted or part of the tractor, along with any implements (Backman, 2013). The ISOBUS standard has achieved many of its objectives, but the system is continuously in developmental stages. New tractor 


\section{Cloud-Based Approach for Tracking and Monitoring of Hay Bales in Smart Agriculture Ilpo Pölönen, Antti Suokannas, Antti Juntunen}

models are now largely called "ISOBUS compatible", meaning that the ISOBUS implements can communicate with the tractor. However, implementations without ISOBUS properties continue flowing into the market.

\section{A Smart Farming Technology Approach to Hay Baling}

In the history of hay baling, moving from hand-held hay bales to the use of a big mechanical baler was an important milestone, not only in hay harvesting, but also in forage conservation (Wilkinsson \& Rinne, 2017). For the first time, grass silage, often the main feed ingredient of dairy cows, could be packed in transportable, homogenous, tradeable, and easily transportable units.

In Finland, the first bale unit packaging trials were done in the 1980s using plastic bags, but soon plastic film replaced the bags. A modern harvesting machine chain comprises mowing, windrowing, baling and, wrapping. Machine chain to harvest grass has shrunk from 3 machines to 1 . Along with the technology change and digitalization, the balers, like other agricultural machines, have changed from robust machines into digitally driven implements that contain computer, numerous sensors, and switches (Figure 1). Practically everything that happens in the baler can be seen on the cabin monitor. Therefore, two developmental steps needed to happen before cloud baling could come into reality: wrapping silage in bales, and digital control and monitoring of baling process.

Smart farming, by definition, signifies decision making based on big data collected and made sense of by smart machines (Wolfert et al., 2017). We developed the system

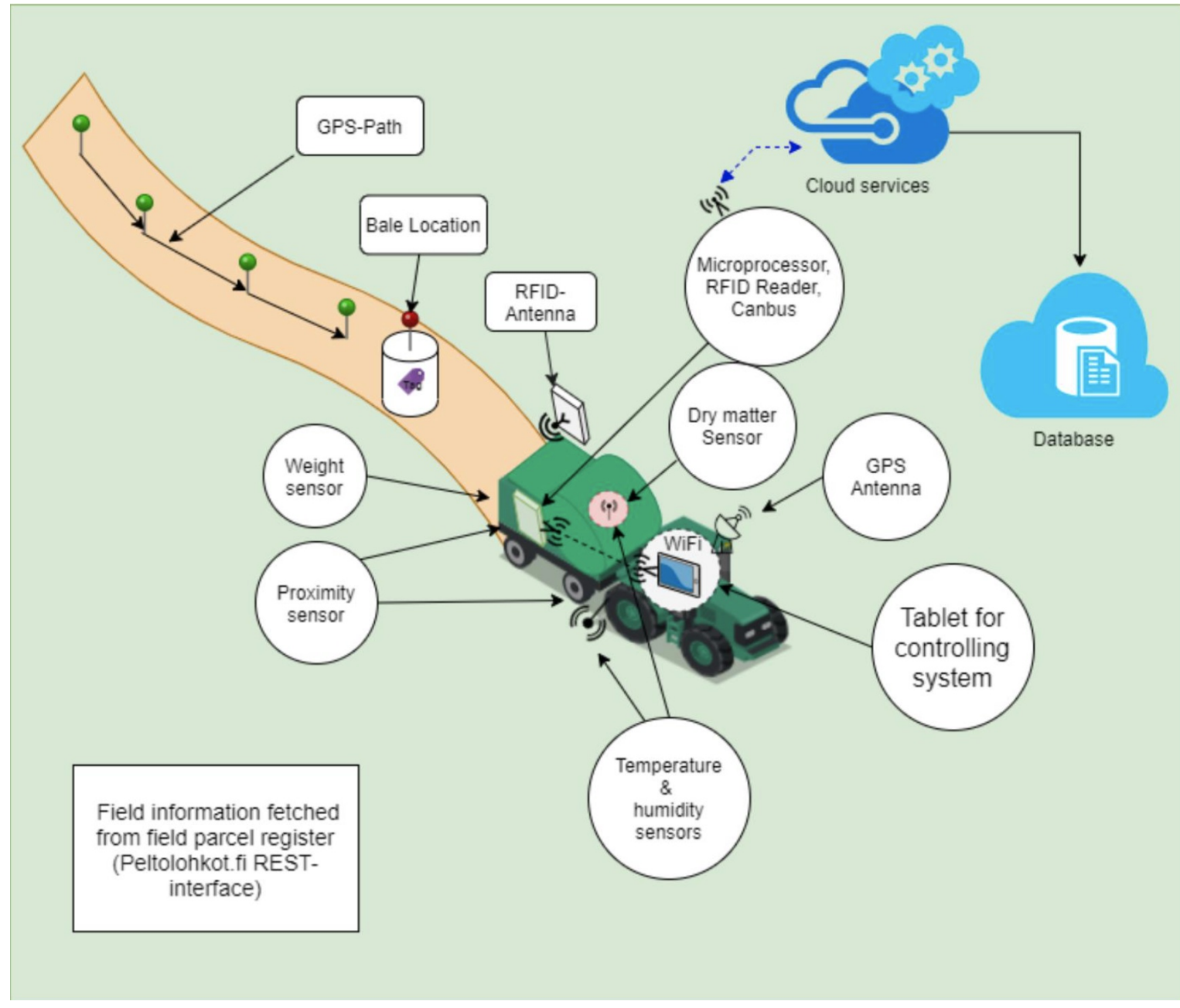

Figure 1. Overview of technical operations in cloud baling. 


\section{Cloud-Based Approach for Tracking and Monitoring of Hay Bales in Smart Agriculture Ilpo Pölönen, Antti Suokannas, Antti Juntunen}

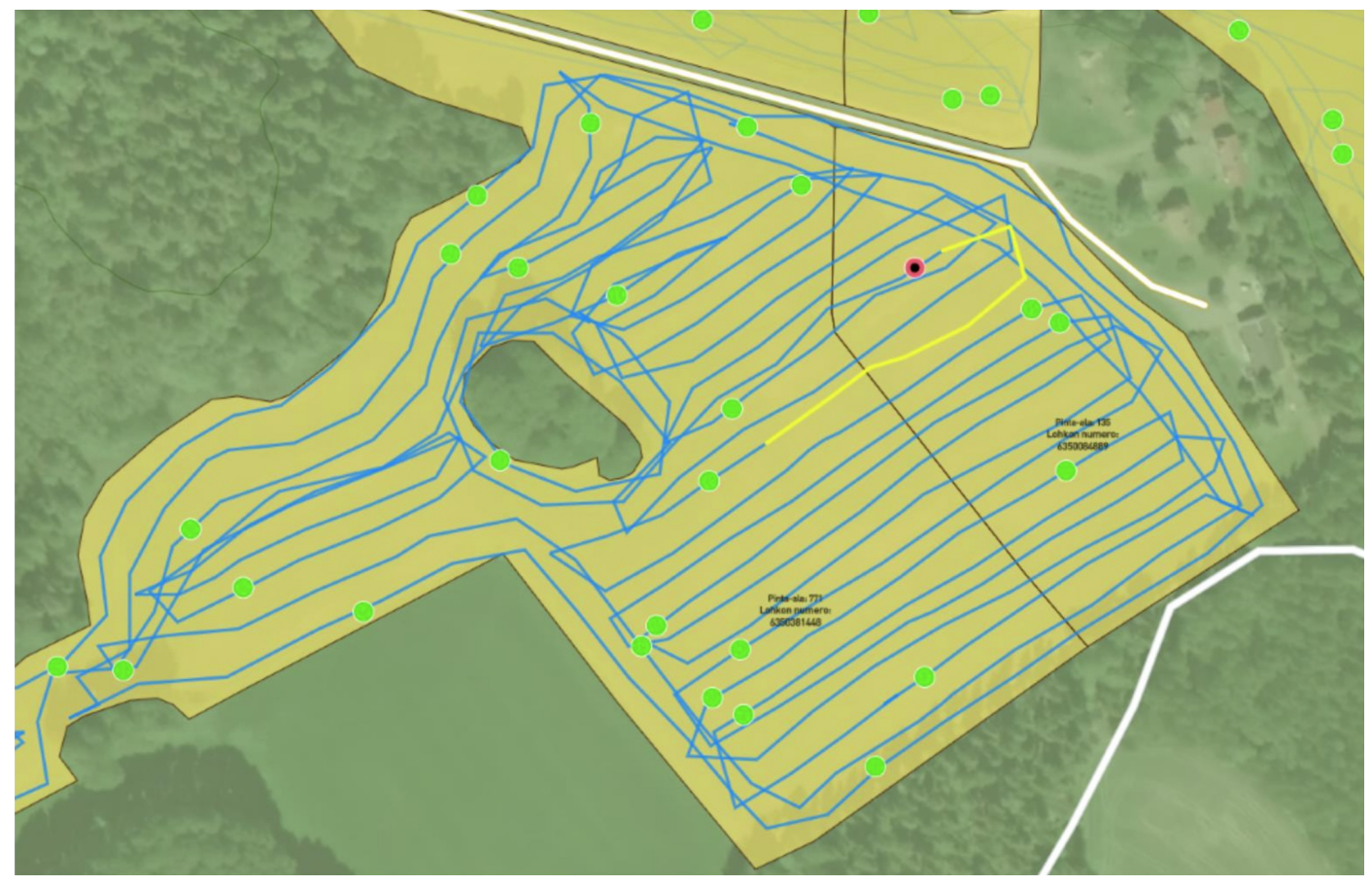

Figure 2. Cloud baling, via farmer's interface application, also produces a map with bale locations and the path baling tractor advanced. Baling can also be followed online. Even though everything is automatic, the user can observe baling on the screen and can intervene by marking problem bales which then appear red on the map.

of cloud baling to lean strongly on IoT because the data is not primarily stored locally, for example, in a baler's memory, but is rather sent to a cloud server online. By measuring yield quantity and quality (weight, dry matter, etc.), and combining it with field parcel data, cloud baling also brings hay baling into the category of precision farming. Not only parcel yield can be calculated, but also each bale's real yield can be estimated using length of a collection path (GPS) and windrow width. Cloud baling, which involves collecting large amounts of hay data into the digital cloud, is not itself an end. Rather, the primary goal is to produce information for a farmer's decision-making process, and their knowledge management (Sørensen et al., 2010).

In our application, there are two levels of information. First, by following baling as it happens online, progress in baling work can be seen (Figure 2). The immediate yield value is also given in a yield report that is available after completing the field parcel's baling (Figure 3). The farmer gets a good overview of what is going on and about the parcel's yield. Second, information from all bales in the yield can be copied from the cloud inventory into a farm management information system (FMIS). In the FMIS, bales become a part of bigger data about the parcel, as well as the whole farm. This information can then be used in planning optimal use of bales during winter feeding and for more accurate crop planning the following season.

\section{A Proposed Solution for Cloud Baling}

In our three-year project, we were able to build a proof of concept (POC) and even pilot the whole information chain of baling. The aim was to utilize RFID tagged bales that enable tracking afterwards. The technology now works, which was documented in Tran and Penttilä (2019). In the system we developed, the data from CANbus, various sensors, switches, and GPS-devices is collected and sent to the server (Penttilä et al., 2019). The biggest benefits of cloud baling come from the online automatic bale inventory. To fully utilize RFID tagged bales would require reading devices positioned along the harvesting-feeding chain with the required software, which we did not develop in this project. Tagged bales are nevertheless already important in bale trade, for example, in horse stables, where the certified origin of 


\section{Cloud-Based Approach for Tracking and Monitoring of Hay Bales in Smart Agriculture Ilpo Pölönen, Antti Suokannas, Antti Juntunen}
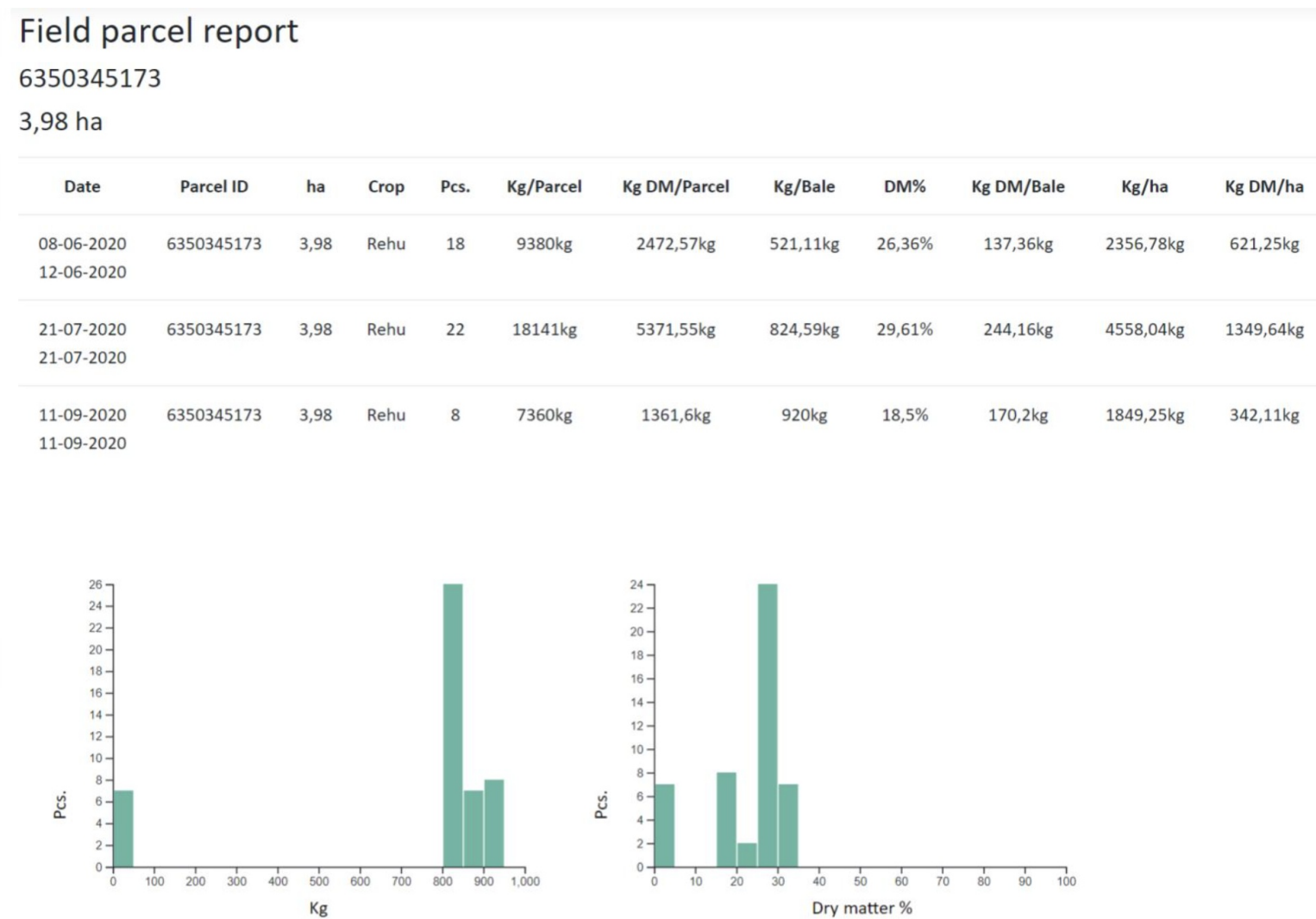

Figure 3. Cloud baling's yield report shows farmer the key parameters of the harvest ie number of bales, average and total amount of fresh and dry mass on the parcel and per hectare for comparison. Variation of bale size and dry matter can be observed by glance from the graphs.

bales is appreciated. Also, where farms are regularly supervised, especially in organic farming, tagged bales would certainly be a benefit.

To our knowledge, tagging hay bales with RFID has been done earlier only with big square bales, which was commercialized by the Agco company (Agco, 2015). The system requires separate tagger machine that mounts tags on the binding twine used for the bales. Our system for round bales in contrast uses factory-made binding that is net equipped with passive RFID tags (not yet commercialized). Field tests and our three-year use of RFID tags confirm that the tags are weatherproof and can be read with near $100 \%$ certainty (Penttilä et al., 2019). An RFID serial number is read during the bale wrapping process, which is merged to the sensor data. A cloud inventory of bales is thereby formed with the real time data for each bale available from all the sensors and the GPS. Additional data such as weather information can be added afterwards.
The process of "cloud baling", as we have defined it, is not a new way of doing things in agriculture, but instead a new way of utilizing existing technology. By creating big data in the informational ecosystem it enables data mining by artificial intelligence (AI), which enhances the development of decision-making. Big data makes for better optimizing of inputs, such as fertilizers and roughage feeding, compared to earlier models.

\section{Bale Inventory: a digitalized field parcel database}

The Finnish Food Authority manages a digitalized field parcel database with an official registry of field parcels. The registry contains official information, of which parcel area is the most important, that is utilized in the administration of agricultural subsidies. In the registry, a farmer has access to only those parcels that are either in the farm's possession or under rental agreement during the growing season. Logging in to the registry requires personal authentication. A fluid process to achieve basic information on field parcels for the cloud baling 


\section{Cloud-Based Approach for Tracking and Monitoring of Hay Bales in Smart Agriculture Ilpo Pölönen, Antti Suokannas, Antti Juntunen}

interface has yet to be determined. This is not currently being done, but is on schedule to be done together with the Finnish Food Authority, in accordance with data protection legislation.

Thus, instead of requiring only a database for each farm, in our system a common national, or even international bale inventory would be formed. The idea is that all bales from each different baler would be stored in the same database. Access to the bales would be limited in the system to the bale owner, with strong authentication. Therefore, not even general calculations, statistics, or research on the bales could be done without farmer permission. In such a widespread scenario, it would be very important to achieve mutual agreement and win-win situations in data management. What we are facing is a global challenge in data ownership that hinders digitalization in general. Not only the farms themselves would benefit from a more open, communal system, but also many of the stakeholders at large.

All activities in the project were carried out principally together with farmers. Our e-commerce application was not developed starting from scratch, but rather utilized existing e-commerce experience. For the increasing needs of roughage trade, due to more fluctuating weather, and hence, varying crop yields, an e-commerce for roughage was developed two years ago by MTK, The Central Union of Agricultural Producers and Forest Owners of Finland. As a result of an API development project with MTK, an application to make sales lot of bales for the e-commerce was produced and is now available for use.

\section{Research Questions for this Project and the Future}

After the initial idea of individualizing hay bales by using a serial number and storing the data in the cloud, we faced a challenge to convince farmers and stakeholders that this system would be useful and lead to versatile benefits. During the project, several research questions emerged while implementing the idea: How does RFID technology function in the baling process? What benefits can users of the system achieve? How much money are they ready to invest in the equipment and for using the service? What stakeholders should we invite to this project? Who owns the data? And how does it all connect to FMIS? Other big questions were how to organize the data storage and what kind of database architecture we should design.

One obvious significant issue was the actual technical implementation. Fortunately, we managed to find solutions to almost all practical problems and research questions. Nevertheless, some new questions and concerns emerged at the end of the project. A challenge to be resolved is who administrates the concentrated database, develops it, and sells the service to farmers and other stakeholders.

As scientists, we would prefer to build a large cloudbased data storage, which could serve users and stakeholders in the best possible way. We have laid the foundation; almost 5,000 round bales are now in the digital bale inventory in the cloud. What should be done next in this field of development?

We believe this PoC, or actually, "pilot" version, can now be developed into a commercial product. Bale manufacturers can start making "cloud balers", that is, equipping balers with this new innovative system. At the same time, both binding net and wrapping plastics with RFID tags should become the new industry standard.

Now that modern baling can build a technology that stores bale information in the cloud, the next project should be to try to solve and develop practices for bale and ecosystem data ownership and usage. Such a project should be international and consist of at least a few baler manufacturers. The objective of such a project would be to produce data management practices that both farmers and stakeholders will accept, and that are in accordance with the most recent international data protection legislation.

\section{Lessons Learned}

What did we learn during this process? Already at the beginning of the project, we should have contacted baler makers' R\&D departments, instead of dealers or local representatives of the brand. Instead of using our own made sensors, including compatible, bulky transformers, we could have received baling data straight from balers' CAN-bus. Even tractors' GPS signals could have been captured from the CAN-bus. We worked with fairly new balers, but only one out of three of them had the dry matter sensors that we particularly needed. Sensors that analyze the crop were still optional and expensive in 2018. Contractors that often invest in advanced technology did not buy accessories then, 


\section{Cloud-Based Approach for Tracking and Monitoring of Hay Bales in Smart Agriculture Ilpo Pölönen, Antti Suokannas, Antti Juntunen}

because they were expensive and farmers did not ask for them. Furthermore, not all farmers recognized the value of the sensors for their business.

\section{Conclusion}

In this project, we developed a new concept and application in smart farming called "cloud baling" for tracking and monitoring the hay baling process. The owners of the bales, farmers, can follow their baling progress on the map screen of a mobile device. An online and de facto inventory of bales thus forms automatically in the cloud with this digital system. The bales in the inventory have quality, quantity, and location measures that establish a good base for ecommerce, and a much-needed tool for roughage trade.

Stamping bales with RFID-tags as such is not a new technique. However, the specific way the data was managed in this project using IoT and creating a local online bale inventory, has not, to our knowledge, been reported earlier. Researchers on this project showed that the RFID-tags are durable and work both on silage bales as well as in practical farm conditions. While tagging bales alone would improve digital crop handling, cloud baling with RFID-tags brings baling further into the category of precision farming. The project not only produced a proof of concept, but also a bale inventory database, along with a roadmap for baler makers to build a commercial application.

The project has received a fair amount of publicity in Finland. Several articles about it both in paper and digital media were published. Also, baling contractors and younger farmers are welcoming cloud baling, and according to a survey are ready to pay for the service. We are now at a stage where different stakeholders are waiting for a commercial application of cloud baling to be developed. This would save farmers a lot of time of with their inventories, which some farmers prioritize as its main advantage.

\section{Acknowledgements}

This three-year research was made possible with funding from the agricultural European Innovation Partnership (EIP-Agri) and Ministry of Agriculture of Finland. Participation of the three dairy farms with their balers in this project is greatly appreciated. They gave their time sometimes even in the middle of busy baling season.

\section{References}

Backman, J. 2013.Navigation System for Modular Agricultural Machines using Optimal Control Methods and Industrial Standard Network. Doctorial Dissertation, Aalto University Publication series, 169/2013.

Palva, R. 2019. Urakointihintakyselyn tuloksia. Prices of agricultural contracting services, a Survey. (In Finnish).

https://www.tts.fi/files/2020/urakointikyselysta_201 8_4.4.2019.pdf

Penttilä, K., Suokannas, A. \& Pölönen, I. 2019. Performance Evaluation of Passive Radio Frequency Identification Technology in Silage Bale Application. Journal of Agricultural Science and Technology, A(9): 120-130.

DOI: 10.17265/2161-6256/2019.02.006

Sørensen, C.G., Fountas, S., Nash, E., Pesonen, L., Boctis, D., Pedersen, S.M., Basso, B. \& Blackmore, S.B. 2010. Conceptual Model of a Future Farm Management Information System. Computers and Electronics in Agriculture, 72(1): 37-47.

Tran, Q.B. \& Penttilä, K. 2019. Digibale -Efficient Silage Bale Lifecycle Management. HAMK Unlimited Journal, 12.3.2019. Retrieved [Jan 8, 2021] from: https://unlimited.hamk.fi/teknologia-jaliikenne/digibale-silage-bale-management

Villa-Henkriksen, A., Edwards, G.T.C., Pesonen, L.A., Green O. \& Sǿrensen, C.A.G. 2020. Internet of Things in arable farming: Implementation, applications, challenges and potential. Biosystems Engineering, 191: 60-84.

DOI: 10.1016/j.biosystemseng.2019.12.013

Wilkinson, J. M. \& Rinne, M. 2018. Highlights of Progress in Silage Conservation and Future Perspectives. Grass and Forage Science, 73(1): 40-52. DOI: $10.1111 /$ gfs.12327

Wolfert, S., Ge, L., Verdouw, C. \& Bogaardt, M-J. 2017. Big Data in Smart Farming -A review. Agricultural Systems, 153: 69-80.

DOI: 10.1016/j.agsy.2017.01.023 


\title{
Cloud-Based Approach for Tracking and Monitoring of Hay Bales in Smart Agriculture Ilpo Pölönen, Antti Suokannas, Antti Juntunen
}

\begin{abstract}
About the Authors
Ilpo Pölönen is an animal nutritionist, a principal research scientist in HAMK Bio Research Unit at Häme University of Applied Sciences. He has a Ph.D. in Animal Science from Helsinki University where he also holds docentship. He graduated from Helsinki University after which he continued Animal Science studies and earned a M.Sc. at Oregon State University. In nutritional research, he has specialized in the preservation of feeds, while during the last years has been involved in developing digital solutions for grass silage. He also teaches masterlevel students in HAMK.
\end{abstract}

Antti Suokannas is a research scientist at the Natural Resources Institute of Finland (Luke). He holds a M.Sc. in Agricultural Technology at Helsinki University. He has a long history of various research projects in forage harvesting technology and has also been involved with work safety studies in plant production. His current research interests include smart farming, automation systems, and forage harvesting processes.

Antti Juntunen is a software developer (B.Sc.) in HAMK Smart research unit at Häme University of Applied Sciences. He has gained experience with many digitalization projects connected to working life. In this project, he was responsible for developing the bale inventory in the cloud and the services connected with it.

Citation: Pölönen, I., Suokannas, A., \&i Juntunen, A. 2021. Cloud-

Based Approach for Tracking and Monitoring of Hay Bales in Smart Agriculture. Technology Innovation Management Review, 11(2): 1723.

http://doi.org/10.22215/timreview/1419

(cc) BY

Keywords: Smart farming, precision farming, big data, RFID, silage, round bales, bale inventory, bale trade 